\title{
Prostate-specific antigen (PSA) screening rates and factors associated with screening in Eastern Canadian men: Findings from cross-sectional survey data
}

\author{
Devan Tchir ${ }^{1}$; Marwa Farag, $\mathrm{PhD}^{1,2}$; Michael Szafron, $\mathrm{PhD}^{1}$ \\ ${ }^{1}$ University of Saskatchewan, School of Public Health, Saskatoon, SK, Canada; ${ }^{2}$ SPADE, Doha Institute for Graduate \\ Studies, Doha, Qatar
}

Acknowledgements/Funding: This work was supported by the TELUS Ride for Dad and the Prostate Cancer Fight Foundation. The views and opinions expressed in this article are strictly the views of the authors and do not necessarily reflect the views of the funders or of Statistics Canada.

Cite as: Can Urol Assoc J 2020 February 4; Epub ahead of print. http://dx.doi.org/10.5489/cuaj.6072

Published online February 4, 2020

$$
* * *
$$

\section{Abstract}

Introduction: The prostate-specific antigen (PSA) test is used in Canada to detect prostate cancer (PCa) despite mixed recommendations. Complications arising from false-positives are common, posing as a cancer-screening concern. This work estimates some Canadian rates of PSA screening and identifies men at increased odds for PSA screening. Methods: The Canadian Community Health Survey (CCHS) from 2009/10 (Atlantic Canada; ATL), 2011/2012 (Ontario; ON), and 2013/2014 (Quebec; QC) were used. Lifetime and recent PSA screening with confidence intervals were constructed to estimate PSA screening in ATL, ON, and QC. Two logistic regression models (for men $<50$ and $\geq 50$ years of age) were used to determine associations between factors and lifetime PSA screening. Results: PSA screening rates have increased in most age groups for ATL, ON, and QC since 2000/2001. Factors positively associated with lifetime PSA screening in men of all ages were: having a digital rectal exam, having a regular doctor, and having a colorectal exam. Fruit and vegetables consumption and non-smoking status were positively associated with lifetime PSA screening in men $<50$ years of age. High income and the presence of chronic health conditions were positively associated with lifetime PSA screening in men $\geq 50$ years of age.

Conclusions: PSA screening rates have generally increased since 2000/2001 in Canada. Physician-related factors play a role in men at all ages, while different factors are associated in men $<50$ years of age and men $\geq 50$ years of age. Limitations include the generalizability 
to all of Canada and the potential for recall bias.

\section{Introduction}

Prostate cancer $(\mathrm{PCa})$ is the most common cancer malignancy and a main cause of cancer death (accounting for 21\%) in Canadian men. ${ }^{1,2}$ While prostate-specific antigen (PSA) blood tests are utilized to detect PCa, most men with elevated blood PSA levels do not have PCa. ${ }^{3}$ Other problems with PSA testing include limited benefits for all-cause and cancer-specific mortality, psychological distress from false positives, and complications from biopsies. ${ }^{4-8}$ Some evidence suggests only 1 in 1000 men screened via PSA testing might prevent $\mathrm{PCa}^{4}$ and only 3 in 1000 men screened will be protected from metastatic PCa. ${ }^{9,} 10$ Therefore, recommendations for PSA screening in Canada are currently mixed and not recommended for men under 50 or over 70 years of age (excepting men at and increased risk for PCa). ${ }^{11,12}$

Despite limitations with PSA testing, it remains the default Canadian PCa screening method and rates may be increasing for men under 50 years of age. ${ }^{13}$ Thus, pending definitive evidence of PSA test benefits, it is important to establish the most recent PSA screening rates in Canada and to determine factors associated with men being screened. To the best of our knowledge, literature documenting Canadian PSA screening rates and factors associated with having a PSA test is either over a decade old for national data ${ }^{14}$ or limited to Alberta. ${ }^{13,15}$ Given that recent Canadian guidelines recommend men to be screened beginning at 50 years of age, ${ }^{12}$ and not under 50 years of age, ${ }^{11,12}$ we aimed to determine screening rates and factors associated with the PSA test in men younger, and older than, 50 years of age.

Our first objective was to compute recent PSA screening rates in Canada and compare them to past Canadian data. Our second objective was to update the current understanding of factors associated with having a PSA test in Canadian, namely by examining the associations between having a PSA screening test and each of several lifestyle-, physician-, and socialrelated variables and whether these associations differed by Canadian region.

\section{Methods}

Secondary data analyses were completed using data from the Canadian Community Health Survey (CCHS). ${ }^{16}$

\section{Data source}

The CCHS is an annual, cross-sectional, validated, population-based survey conducted inperson and via telephone, intended to inform health policy for Canadian communities. ${ }^{16}$ Men who answered the optional PSA screening content on the CCHS were included for the analyses. The last CCHS cycle to include PSA relevant questions was 2015/2016, limited to men from Nova Scotia (NS) and Newfoundland (NL). The next recent cycle from 2013/2014 was limited to men 35 years and older from Quebec (QC). For this reason, we also included the 2009/2010 and 2011/2012 CCHSs, because the 2009/2010 CCHS has PSA related 
questions for men 35 years and older from Newfoundland (NL), Prince Edward Island (PEI), and Nova Scotia (NS), hereafter referred to as Atlantic Canada (ATL), and the 2011/2012 CCHS because it has PSA relevant questions and men 35 years and older from Ontario $(\mathrm{ON})$, to be representative of Eastern Canada. The response rates for PSA relevant questions were $41.6 \%, 41.7 \%$, and $43.1 \%$ for ATL, ON, and QC, respectively. We dropped the 2015/2016 cycle because many of the variables of interest differed from the 2009-2014 cycles.

\section{Outcome and study variables}

The outcome variables for the study were the prevalences for lifetime and recent (within one year) PSA screening in Eastern Canada. Factors associated with lifetime PSA screening were identified from the literature. Lifestyle-related variables included in the analyses are alcohol consumption ${ }^{17}$ in the last 12 months, BMI, ${ }^{18,19}$ daily consumption of fruits and vegetables, ${ }^{20}$ type of smoker, ${ }^{14}$ self-perceived health, ${ }^{21}$ and physical activity. ${ }^{17}$ Having a regular doctor, ${ }^{14}$ ever having a DRE, ${ }^{22}$ and receiving a $\mathrm{CRE}^{15,17}$ were physician-related factors included in the analyses. Other social and health-related independent variables considered were needing help with daily activities, ${ }^{17}$ marital status, ${ }^{14}$ urinary incontinence (a potential urinary tract problem), ${ }^{23}$ the number of chronic health conditions, ${ }^{15}$ country of birth, ${ }^{14}$ and spoken language. ${ }^{14}$ Control variables used were age, ethnicity, household income, and education. ${ }^{14}$, ${ }^{15}$ Refer to Table 1 or Table 2 for the list of the variables utilized in our analyses.

\section{Statistical methods}

The three datasets were combined and weights were standardized for the combined dataset. Descriptive statistics and regression modeling were performed on the weighted data with SAS v9.4. Prevalence estimates of lifetime and recent (within one year) PSA screening with 95\% confidence intervals (CIs) were calculated for each survey. We constructed $95 \%$ CIs for the weighted prevalences of men $40-49,50-59,60-69, \geq 70, \geq 50$ and $\geq 40$ years of age. We formed one logistic model for men aged $<50$ years of age and another model for men $\geq 50$ years of age. To determine which variables were associated with the outcome variable, bivariate logistic regression analyses of each independent variable with the outcome variable were completed first. Those pairs with $P<0.20$ were to be included in the logistic regression model. All variance inflation factor (VIF) scores were below 2.5, indicating a negligible influence of multicollinearity. Interaction terms for these variables and the region of respondent (ATL, ON, QC) were included if $P<0.05$, given that the region of the respondent might differentially influence the independent variables on the outcome variable. Influential points were removed as described by Ryan et al. ${ }^{24}$ Binary logistic regression was used to build our final models for the combined 2009/2010, 2011/2012, 2013/2014 CCHS data with a 0.05 significance level. Individuals with missing data were deleted case-wise; variables with greater than 5\% missing data were excluded. Daily consumption of fruits and 
vegetables in the $\geq 50$ years old model was excluded because of too many missing observations $(>5 \%)$. The need for ethics approval was unnecessary because of the secondary analyses of publicly available, de-identified data.

\section{Results}

The total sample size of the combined dataset was 22,048. The demographic information of men $<50$ years of age and $\geq 50$ years of age can be respectively found in Tables 1 and 2 . Note that a higher proportion of men $\geq 50$ years of age have been screened with the PSA test, DRE, and CRE compared to men $<50$ years of age $(59.72 \%, 74.83 \%, 63.23 \%$ compared to $16.57 \%, 30.23 \%$, and $19.78 \%$, respectively). The proportion of men having multiple chronic conditions was greater in the $\geq 50$ years of age group compared to the $<50$ years of age group $(P<0.0001)$.

Prevalence rates with $95 \%$ CIs of lifetime and recent PSA screening (i.e. last year), respectively, by region and age can be found in Tables 3 and 4. From these tables, men in ATL and ON have higher lifetime screening rates than men in QC. No such statistical differences existed in recent (last year) screening rates across the three regions. Over half of men aged $\geq 40$ from ATL and QC have had a PSA screening test. Approximately a quarter of men aged $\geq 40$ from ATL, ON and QC have had a PSA screening test in the last year and over one-third of men aged $\geq 70$ from ATL, ON and QC have had a PSA screening test in the last year. Estimates, odds ratios (ORs) and 95\% CIs of independent variables in the final logistic regression models for the $<50$ year old men and of $\geq 50$ year old men can be found in Tables 5 and 6 , respectively.

For the $<50$ years of age model (Table 5): Men who have had a DRE $(P<0.0001)$, are non-smokers $(P<0.0001)$, and who consume fruits and vegetables more than 10 times per day $(P=0.0005)$ had higher odds of being screened with the PSA test. It was found that men in $\mathrm{ON}$ and QC with regular doctors had higher odds of being screened than men in $\mathrm{ON}$ and $\mathrm{QC}$ without regular doctors $(P=0.0001, P<0.0001$, respectively).

For the $\geq 50$ model (Table 6): Men in households earning 20,000-39,999 CAD and $<20,000 \mathrm{CAD}$ had decreased odds of having been screened with the PSA test compared to men with household incomes exceeding 80,000 $\mathrm{CAD}(P=0.0104, P=0.0153$, respectively). Men with a regular doctor $(P<0.0001)$, who have had a DRE $(P<0.0001)$ and who have had a CRE $(P<0.0001)$ had higher odds of being screened with the PSA test. Obese men had higher odds of having been screened with a PSA test than normal/underweight men $(P=0.0030)$. Men who perceived their health to be good, fair, or poor had decreased odds of having been screened compared to men who perceived their health to be very good or excellent $(P=0.0298, P<0.0001, P=0.0052$, respectively). Men with one and two or more chronic health conditions had higher odds of being screened with a PSA test than men without chronic health conditions ( $P=0.0026, P=0.0302$, respectively). 

PSA screening rates survey

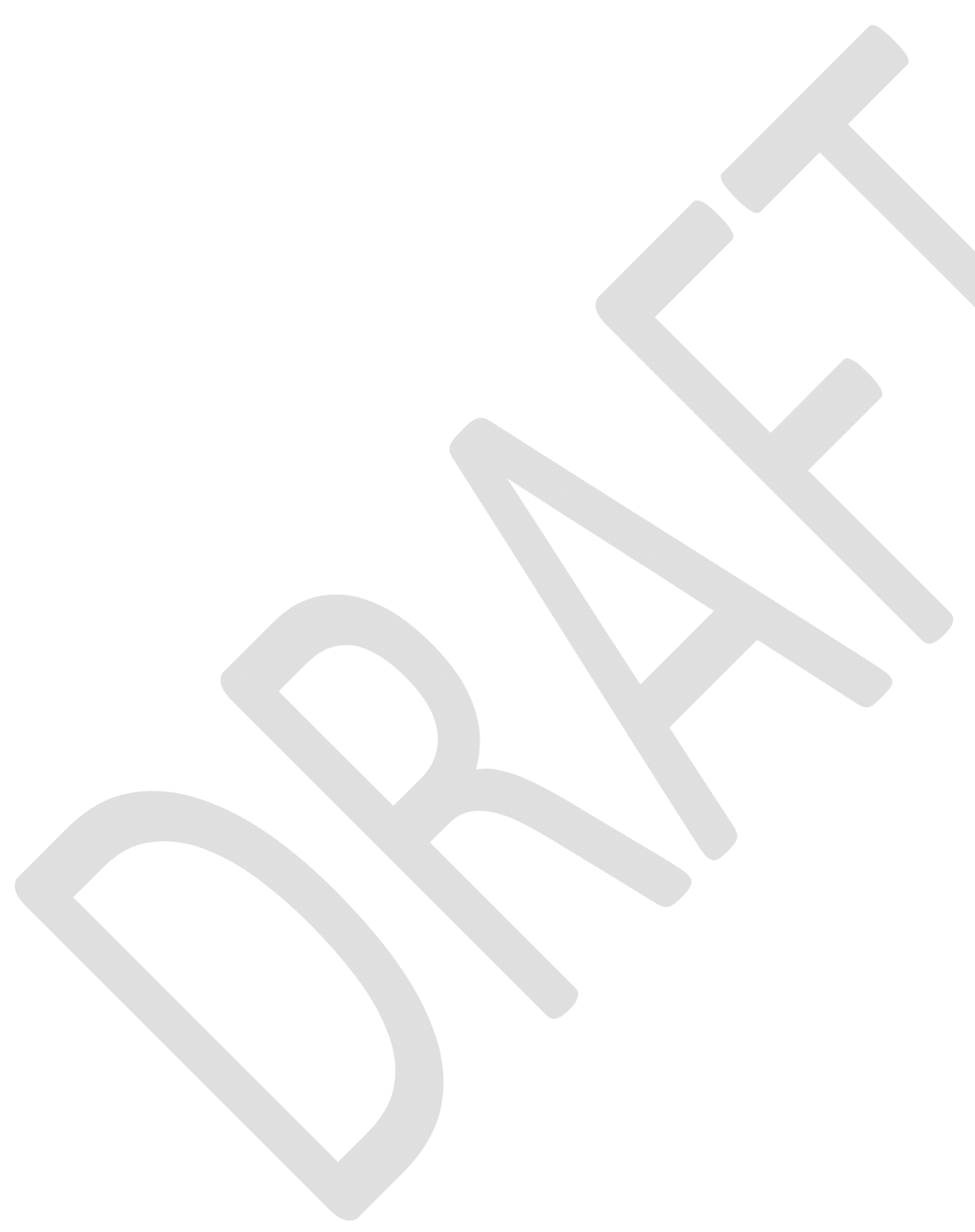




\section{Discussion}

This study examined lifetime and recent PSA screening rates, and factors associated with lifetime PSA screening in Eastern Canadian men aged 35 and older. We were interested in estimating rates of ever having and having a recent (within the last year) PSA screening test in Eastern Canada. We identified factors associated with PSA screening among men younger than 50 or at least 50 years of age.

We hypothesized there would be no substantial increase in PSA screening rates, given that no overwhelming evidence has suggested that the test is beneficial. We computed lifetime and recent PSA screening rates in Eastern Canada. In our Table 3, we present the lifetime PSA screening rates for ATL (2009/2010), ON (2011/2012), and QC (2013/2014) for different age groups. Recent (within the last year) screening rates from the United States are similar to ours during the same time frame. Vetterlein et al. report that $38.9 \%$ of men in 2012 and $35.8 \%$ of men in 2014 were recently screened. ${ }^{25}$ When we compare the corresponding 2000/2001 ${ }^{14}$ rates for NL, PEI, and NS to our Atlantic Canada rates (cf. Table 3 ), the 2000/2001 rates are generally lower than our Atlantic Canada rates except for men aged 40-49 from NS. ${ }^{14}$ The 2000/2001 ON rates, regardless of age category, are lower than ours (cf. Table 3). For the 2000/2001 QC rates, only the rates for men aged 60-69 years are lower than our rates (cf. Table 3). Despite the PSA screening controversy, our results suggest that since 2000/2001, the rates of lifetime PSA screening have generally increased in ATL, ON, and QC for men $\geq 40$ years of age (with the exceptions of those noted). Given that screening continues for men $<50$ or $\geq 70$ years of age is concerning, especially because screening these age groups is not recommended in Canada (excepting men at an increased risk).

Based on the factors associated with PSA screening, we hypothesized that having a regular doctor; a digital rectal exam; a colorectal exam; independence in activities; urinary incontinence; obesity status; good perceived health; physical activity; fruits and vegetable consumption (as a proxy for healthy lifestyle); alcohol use; chronic health conditions; married/equivalent status; non-smoking status; been born in Canada; and a English/French spoken language at home would be positively associated with having a PSA test, while controlling for age, income, education, ethnicity, and regional differences. In Table 5 and Table 6 respectively, we present the models for ever having had a PSA screening test for men $<50$ and men $\geq 50$ years of age. Physician-related factors (having a regular doctor, a CRE, and a DRE) were significantly positively associated in both models. Their presence in both models speaks to the role physicians play in PSA screening among men of all ages. ${ }^{22}$, 23,26-30 This could suggest regular physicians are prompting men of all ages to be screened. In fact, the literature supports this because the decision to have a PSA test is heavily influenced by physicians' recommendation. ${ }^{22,27,28}$ 
In men $\geq 50$ years of age only, we found positive associations with increased income, obesity, very good or better perceived health, and the presence of chronic health conditions and having a lifetime PSA screening test. Higher income in older men predicted PSA screening. Other Canadian studies have found a positive association between income and PSA screening. ${ }^{13-15}$ Obesity was associated with PSA screening, consistent with prior literature. ${ }^{18,19,31,32}$ This might be because physicians are more likely to offer PSA tests to overweight male patients. ${ }^{18}$ Physicians complete more technical tasks (i.e. prescribing a diagnostic plan, discussing lab work, etc.) than other tasks with obese patients ${ }^{33}$ which likely would include PSA screening. Men with lower self-perceived health had decreased odds of being screened, which has been found in prior literature documenting PSA screening. ${ }^{15,34}$ Chronic health conditions predicted PSA screening as has been documented previously in Canada. ${ }^{15}$

In men $<50$ years of age only, we found associations with smoking (-) and consumption of fruits and vegetables $(+)$ with having a lifetime PSA screening test. These findings are consistent with the literature for PSA screening among non-smokers ${ }^{14}$ and fruit and vegetable consumption in colorectal screening ${ }^{20}$ and could suggest that men who are concerned about their health might seek having a PSA screening test. Paradoxically, for men in ON and QC under 50 years of age, there is an increased odds of having a PSA screening test and having regular doctors. Further research is warranted here, given that no Canadian guidelines advocate for screening under 50 years of age (excepting those at an increased risk).

When comparing both the $<50$ years of age model and the $\geq 50$ years of age model, some themes emerge. Physician-related factors were important for both models, indicating the role physicians have in the PSA screening process. Among men aged $<50$ years, factors which are related to leading a healthy lifestyle (non-smoking, high fruit and vegetable consumption) seem to play a role in PSA screening. This might indicate that these healthy individuals initiate physician contact and subsequent PSA screening. Conversely, among men $\geq 50$ years of age, non-behavioural-related factors which predict physician interaction (i.e. having chronic health conditions ${ }^{35}$ or high income ${ }^{36}$ ) were found to be significant, suggesting non-behavioural factors are initiating physician contact and subsequent PSA screening in older men. These factors are also related to those described by Andersen. ${ }^{37,38}$ Access to health services (i.e. the PSA test) is likely facilitated or impeded by enabling factors (i.e. income) and/or health beliefs (i.e. valuing a healthy lifestyle).

Given the risks associated with PSA screening and its lack of efficacy in identifying PCa, along with our work showing that a large proportion of males are being screened in nonrecommended age groups while possibly being prompted by their physicians, it is evident that PSA screening is a growing public health concern. 


\section{Limitations}

Responses were self-reported via the CCHS (i.e. ever having taken a PSA test). Therefore, recall bias might have been a factor. Two factors which were not assessed in this work but were assessed in 2000/2001 ${ }^{14}$ were urban/rural status and employment status. Employment status was not considered for this work given the very low response rate on the CCHS.

Because lifetime screening was used as the outcome variable, some responses might have changed since the PSA test was taken. ${ }^{14}$ For example, a man might have been screened with the PSA test and many years afterwards developed multiple chronic conditions. Lastly, this work was confined to ATL, ON and QC and thus may not generalize to all of Canada.

\section{Conclusions}

This study investigated screening rates for the PSA test in Canadian men, and factors associated with whether Canadian men have ever been screened with the PSA test. We found that rates of PSA screening have generally increased since 2000/2001 in the regions defined for this work (ATL, ON, and QC). We report that physician-related factors are important for the PSA screening of men of all ages. There might also be important differences among men aged $<50$ years of age and men $\geq 50$ years of age. These results, coupled with the finding that screening rates have generally increased since 2000/2001, demonstrates that physicians continue to play an important role in PSA screening and that despite mixed recommendations for PSA screening, rates continue to rise. The fact that a large portion of men $<50$ years of age and $\geq 70$ years of age continue to be screened deserves a closer inspection from policy makers.

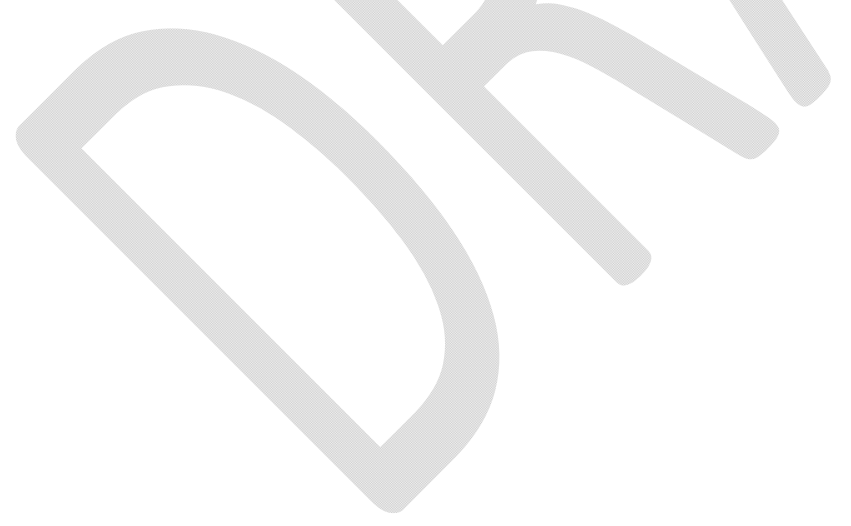




\section{References}

1. Attard G, Parker C, Eeles RA, et al. Prostate cancer. Lancet 2016;387:70-82.

2. Canadian Cancer Society's Advisory Committee on Cancer Statistics. Canadian Cancer Statistics 2016. Toronto, ON: Canadian Cancer Society; 2016 [cited 2019 May]. Available from:http://www.cancer.ca/ /media/cancer.ca/CW/cancer\%20information/cancer\% 20101/Canadian\%20cancer\%20statistics/Canadian-Cancer-Statistics-2016-EN.pdf

3. Lilja H, Ulmert D, Vickers AJ. Prostate-specific antigen and prostate cancer: prediction, detection and monitoring. Nat Rev Cancer 2008;8:268-78.

4. Moyer VA. Screening for prostate cancer: US Preventive Services Task Force recommendation statement. Ann Intern Med 2012;157:120-34.

5. Djulbegovic M, Beyth RJ, Neuberger MM, et al. Screening for prostate cancer: systematic review and meta-analysis of randomised controlled trials. BMJ 2010;341:c4543.

6. Pron G. Prostate-Specific Antigen (PSA)Based Population Screening for Prostate Cancer: An Evidence-Based Analysis. Ont Health Technol Assess Ser 2015;15:1-64.

7. Scott JG, Friedman EK, Ferrante JM. Emotional consequences of persistently elevated PSA with negative prostate biopsies. Am J Cancer Prev 2013;1:4-8.

8. McNaughton-Collins M, Fowler FJ, Caubet JF, et al. Psychological effects of a suspicious prostate cancer screening test followed by a benign biopsy result. Am J Med 2004;117:719- 25.

9. Schröder FH, Hugosson J, Roobol MJ, et al. Screening and prostate cancer mortality: results of the European Randomised Study of Screening for Prostate Cancer (ERSPC) at 13 years of follow-up. Lancet. 2014;384:2027-35.

10. Fenton JJ, Weyrich MS, Durbin S, et al. Prostate-specific antigen-based screening for prostate cancer: evidence report and systematic review for the US Preventive Services Task Force. JAMA 2018;319:1914-31.

11. Bell N, Gorber SC, Shane A, et al. Canadian Task Force on Preventive Health Care. Recommendations on screening for prostate cancer with the prostate-specific antigen test. CMAJ 2014;186:1225-34.

12. Rendon RA, Mason RJ, Marzouk K, et al. Canadian Urological Association recommendations on prostate cancer screening and early diagnosis. CUAJ 2017;11:298-309.

13. Gorday W, Sadrzadeh H, de Koning L, et al. Association of sociodemographic factors and prostate-specific antigen (PSA) testing. Clin Biochem 2014;47:164-9.

14. Beaulac JA, Fry RN, Onysko J. Lifetime and recent prostate specific antigen (PSA) screening of men for prostate cancer in Canada. Can J Public Health 2006;97:171-6.

15. Richardson H, Aronson KJ, James A, et al. Factors related to use of prostate cancer screening: the Alberta Tomorrow Project. Open Med 2007;1:e3-e12.

16. Statistics Canada. Community health survey - annual component (CCHS). 2009-2014. Available online at: http://www23.statcan.gc.ca/imdb/p2SV.pl?Function= getSurvey\&Id=259374.

17. Drazer MW, Huo D, Schonberg MA, et al. Population-based patterns and predictors of prostate-specific antigen screening among older men in the United States. J Clin Oncol 2011;29:1736-43.

18. Fontaine KR, Heo M, Allison DB. Obesity and prostate cancer screening in the USA. Public Health 2005;119:694-8. 
19. Fowke JH, Signorello LB, Underwood III W, et al. Obesity and prostate cancer screening among African-American and Caucasian men. Prostate 2006;66:1371-80.

20. Seeff LC, Nadel MR, Klabunde CN, et al. Patterns and predictors of colorectal cancer test use in the adult US population. Cancer 2004;100:2093-103.

21. Avery KN, Blazeby JM, Lane JA, et al. Decision-making about PSA testing and prostate biopsies: a qualitative study embedded in a primary care randomised trial. Eur Urol 2008;53:1186-93.

22. Allard CB, Dason S, Lusis J, et al. Prostate cancer screening: Attitudes and practices of family physicians. CUAJ 2013;6:188-93.

23. Gattellari M, Young JM, Ward JE. GP and patient predictors of PSA screening in Australian general practice. Fam Pract 2003;20:294-303.

24. Ryan BL, Koval J, Corbett B, et al. Assessing the impact of potentially influential observations in weighted logistic regression. The Research Data Centres Information and Technical Bulletin: Statistics Canada. 2015.

25. Vetterlein MW, Dalela D, Sammon JD, et al. State-by-state Variation in Prostate-specific Antigen Screening Trends Following the 2011 United States Preventive Services Task Force Panel Update. Urology 2018;112:56-65.

26. Nair-Shalliker V, Bang A, Weber M, et al. Factors associated with prostate specific antigen testing in Australians: Analysis of the New South Wales 45 and Up Study. Sci Rep 2018;8:4261.

27. Pucheril D, Dalela D, Sammon J, et al. The influence of physician recommendation on prostate-specific antigen screening. Urol Oncol 2015;33:424.e1-7.

28. So WK, Choi KC, Tang WP, et al. Uptake of prostate cancer screening and associated factors among Chinese men aged 50 or more: a population-based survey. Cancer Biol Med 2014;11:56-63.

29. Ross LE, Taylor YJ, Richardson LC, et al. Patterns in prostate-specific antigen test use and digital rectal examinations in the Behavioral Risk Factor Surveillance System, 2002-2006. $J$ Natl Med Assoc 2009;101:316-24.

30. Ross LE, Taylor YJ, Howard DL. Trends in prostate-specific antigen test use, 2000-2005. Public Health Rep 2011;126:228-39.

31. Patel K, Kenerson D, Wang H, et al. Factors influencing prostate cancer screening in lowincome African Americans in Tennessee. J Health Care Poor Underserved 2010;21:114- 26.

32. Nderitu P, Van Hemelrijck M, Ashworth M, et al. Prostate-specific antigen testing in inner London general practices: are those at higher risk most likely to get tested?. BMJ open 2016;6:e11356.

33. Bertakis KD, Azari R. The impact of obesity on primary care visits. Obes Res 2005;13:161523.

34. Essink-Bot ML, de Koning HJ, Nijs HG, et al. Short-term effects of population-based screening for prostate cancer on health-related quality of life. J Natl Cancer Inst 1998;90:925-31.

35. Broemeling AM, Watson DE, Prebtani F. Population patterns of chronic health condi- tions, co-morbidity and healthcare use in Canada: implications for policy and practice. Healthc $Q$ 2008;11:70-6.

36. Lasser KE, Himmelstein DU, Woolhandler S. Access to care, health status, and health disparities in the United States and Canada: results of a cross-national population-based survey. 
Am J Public Health 2006;96:1300-7.

37. Andersen RM, Newman JF. Societal and individual determinants of medical care utilization in the United States. Milbank Mem Fund Q Health Soc 1973;51:95-124.

38. Andersen RM. Revisiting the behavioral model and access to medical care: does it matter? $J$ Health Soc Behav 1995;36:1-10. 


\section{Figures and Tables}

\begin{tabular}{|c|c|}
\hline Respondent characteristics & $\begin{array}{c}\text { CCHS data } \\
\text { n (weighted \%) }\end{array}$ \\
\hline \multicolumn{2}{|l|}{ Lifetime PSA screening $^{\dagger}$} \\
\hline $\begin{array}{l}\text { Yes (screened for family history, regular checkup, or } \\
\text { for age) }\end{array}$ & $929(16.57)$ \\
\hline No & $5238(83.43)$ \\
\hline \multicolumn{2}{|l|}{ Age $^{*}$} \\
\hline $35-39$ & $2094(31.65)$ \\
\hline $40-44$ & $2147(33.58)$ \\
\hline $45-49$ & $1926(34.77)$ \\
\hline Missing & 0 \\
\hline \multicolumn{2}{|l|}{ Household income* } \\
\hline$<20000 \mathrm{CAD}$ & $395(5.21)$ \\
\hline 20 000-39 999 CAD & $835(11.61)$ \\
\hline 40 000-59999 CAD & $984(15.13)$ \\
\hline $60000-79999 \mathrm{CAD}$ & $970(16.21)$ \\
\hline$\geq 80000 \mathrm{CAD}$ & $2916(51.37)$ \\
\hline Missing & $67(0.48)$ \\
\hline \multicolumn{2}{|l|}{ Educational attainment $^{\dagger}$} \\
\hline Low (some post-secondary or less) & $1807(27.59)$ \\
\hline High (post-secondary certificate) & $4195(69.64)$ \\
\hline Missing & $165(2.77)$ \\
\hline \multicolumn{2}{|l|}{ Ethnicity* } \\
\hline White & $4957(70.37)$ \\
\hline Visible minority & $952(25.68)$ \\
\hline Missing & $258(3.94)$ \\
\hline \multicolumn{2}{|l|}{ Has a regular doctor ${ }^{*}$} \\
\hline Yes & $4921(80.39)$ \\
\hline No & $1243(19.59)$ \\
\hline Missing & $3(0.02)$ \\
\hline \multicolumn{2}{|l|}{ Had a digital rectal exam* } \\
\hline Yes & $1879(30.23)$ \\
\hline No & $4264(69.50)$ \\
\hline Missing & $24(0.27)$ \\
\hline \multicolumn{2}{|l|}{ Had a colorectal exam ${ }^{\dagger}$} \\
\hline Yes (had a fecal occult blood test, sigmoidoscopy, or & $1220(19.78)$ \\
\hline
\end{tabular}




\begin{tabular}{|c|c|}
\hline colonoscopy) & \\
\hline No & $4922(79.87)$ \\
\hline Missing & $25(0.36)$ \\
\hline \multicolumn{2}{|l|}{ Needs help with daily activities ${ }^{\dagger}$} \\
\hline $\begin{array}{l}\text { Yes (with preparing meals, making appointments, } \\
\text { doing housework, personal care, moving within the } \\
\text { house, or personal finances) }\end{array}$ & $294(3.41)$ \\
\hline No & $5872(96.57)$ \\
\hline Missing & $1(0.02)$ \\
\hline \multicolumn{2}{|l|}{ Has urinary incontinence ${ }^{*}$} \\
\hline Yes & $43(0.54)$ \\
\hline No & $6119(99.39)$ \\
\hline Missing & $5(0.07)$ \\
\hline Body mass index $(\mathrm{BMI})^{\dagger}$ & +2 \\
\hline Normal/underweight $(<25)$ & $1981(33.49)$ \\
\hline Overweight (25-29.9) & $2634(42.90)$ \\
\hline Obese $(\geq 30)$ & $1481(22.25)$ \\
\hline Missing & $71(1.36)$ \\
\hline Perceived health ${ }^{\dagger}$ & \\
\hline Poor & $123(1.39)$ \\
\hline Fair & $412(5.96)$ \\
\hline Good & $1814(30.73)$ \\
\hline Very good/excellent & $3816(61.91)$ \\
\hline Missing & $2(0.02)$ \\
\hline \multicolumn{2}{|l|}{ Physical activity $^{*}$} \\
\hline Active & $1662(24.46)$ \\
\hline Moderately active & $1633(24.59)$ \\
\hline Inactive & $2865(50.83)$ \\
\hline Missing & $7(0.13)$ \\
\hline \multicolumn{2}{|l|}{ Type of smoker ${ }^{\dagger}$} \\
\hline Current smoker & $1807(27.08)$ \\
\hline Former/never smoker & $4310(72.26)$ \\
\hline Missing & $50(0.66)$ \\
\hline \multicolumn{2}{|l|}{ Daily consumption of fruits and vegetables ${ }^{*}$} \\
\hline$<5$ times per day & $4097(66.56)$ \\
\hline $5-10$ times per day & $1704(27.34)$ \\
\hline$>10$ times per day & $176(3.68)$ \\
\hline Missing & $190(2.42)$ \\
\hline Marital status ${ }^{\dagger}$ & \\
\hline
\end{tabular}




\begin{tabular}{|l|c|} 
Married/equivalent & $4023(76.04)$ \\
\hline Single & $2137(23.66)$ \\
\hline Missing & $7(0.30)$ \\
\hline Country of birth & \\
\hline Canada & $4848(66.09)$ \\
\hline Other & $1070(30.25)$ \\
\hline Missing & $249(3.66)$ \\
\hline Number of chronic health conditions & \\
\hline 0 & $3834(65.74)$ \\
\hline 1 & $1450(22.25)$ \\
\hline$\geq 2$ & $878(11.97)$ \\
\hline Missing & $5(0.04)$ \\
\hline Alcohol usage in the last 12 months & \\
\hline Yes & $5254(83.36)$ \\
\hline No & $782(14.54)$ \\
\hline Missing & $131(2.10)$ \\
\hline Spoken language & \\
\hline $\begin{array}{l}\text { Native (English at home in ATL and ON; } \\
\text { French at home in QC) }\end{array}$ & $5456(82.73)$ \\
\hline $\begin{array}{l}\text { Non-native (English at home in QC; French at } \\
\text { home in ATL and ON) }\end{array}$ & $185(4.13)$ \\
\hline Other (foreign language at home) & $305(9.69)$ \\
\hline Missing & $221(3.45)$ \\
\hline Region (CCHS year) & \\
\hline ATL (2009/10) & $883(7.05)$ \\
\hline ON (2011/12) & $3528(59.16)$ \\
\hline QC (2013/14) & $1756(33.79)$ \\
\hline Missing & 0 \\
\hline & \\
\hline
\end{tabular}

${ }^{*}$ Taken directly from the CCHS. ${ }^{\dagger}$ Derived from the CCHS. ${ }^{\S}$ Derived from chronic health conditions on the CCHS which include asthma, fibromyalgia, high blood pressure, migraines, chronic obstructive pulmonary disorders, diabetes, heart disease, cancer, intestinal/stomach ulcers, ailments from stroke, bowel disorder, bowel disease, mood disorders, and anxiety disorders. CCHS: Canadian Community Health Survey; PSA: prostate-specific antigen. 


\begin{tabular}{|c|c|}
\hline Respondent characteristics & $\begin{array}{c}\text { CCHS data } \\
\text { n (weighted \%) }\end{array}$ \\
\hline \multicolumn{2}{|l|}{ Lifetime PSA screening $^{\dagger}$} \\
\hline $\begin{array}{l}\text { Yes (screened for family history, regular checkup, or } \\
\text { for age) }\end{array}$ & $9727(59.72)$ \\
\hline No & $6154(40.28)$ \\
\hline \multicolumn{2}{|l|}{ Age* } \\
\hline $35-39$ & $5366(44.58)$ \\
\hline $40-44$ & $5672(32.32)$ \\
\hline $45-49$ & $4843(23.10)$ \\
\hline Missing & 0 \\
\hline Household income $^{*}$ & +2 \\
\hline$<20000 \mathrm{CAD}$ & $1603(7.30)$ \\
\hline 20 000-39 999 CAD & $4120(19.93)$ \\
\hline 40 000-59 999 CAD & $3469(20.26)$ \\
\hline 60 000-79 999 CAD & $2414(15.63)$ \\
\hline$\geq 80000 \mathrm{CAD}$ & $4048(35.95)$ \\
\hline Missing & $227(0.93)$ \\
\hline \multicolumn{2}{|l|}{ Educational attainment ${ }^{\dagger}$} \\
\hline Low (some post-secondary or less) & $6848(39.19)$ \\
\hline High (post-secondary certificate) & $8514(57.31)$ \\
\hline Missing & $519(3.50)$ \\
\hline \multicolumn{2}{|l|}{ Ethnicity* $^{*}$} \\
\hline White & $14054(82.82)$ \\
\hline Visible minority & $1084(12.13)$ \\
\hline Missing & $743(5.06)$ \\
\hline \multicolumn{2}{|l|}{ Has a regular doctor ${ }^{*}$} \\
\hline Yes & $14391(89.42)$ \\
\hline 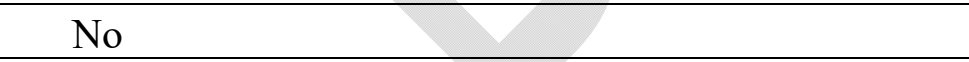 & $1484(10.56)$ \\
\hline Missing & $6(0.03)$ \\
\hline \multicolumn{2}{|l|}{ Had a digital rectal exam* ${ }^{*}$} \\
\hline Yes & $12325(74.83)$ \\
\hline No & $3477(24.72)$ \\
\hline Missing & $79(0.45)$ \\
\hline \multicolumn{2}{|l|}{ Had a colorectal exam ${ }^{\dagger}$} \\
\hline $\begin{array}{l}\text { Yes (had a fecal occult blood test, sigmoidoscopy, or } \\
\text { colonoscopy) }\end{array}$ & $10455(63.23)$ \\
\hline
\end{tabular}




\begin{tabular}{|c|c|}
\hline No & $5331(36.17)$ \\
\hline Missing & $95(0.59)$ \\
\hline \multicolumn{2}{|l|}{ Needs help with daily activities ${ }^{\dagger}$} \\
\hline $\begin{array}{l}\text { Yes (with preparing meals, making appointments, } \\
\text { doing housework, personal care, moving within the } \\
\text { house, or personal finances) }\end{array}$ & $1658(8.69)$ \\
\hline No & $14217(91.28)$ \\
\hline Missing & $6(0.02)$ \\
\hline \multicolumn{2}{|l|}{ Has urinary incontinence ${ }^{*}$} \\
\hline Yes & $809(3.87)$ \\
\hline No & $15037(96.00)$ \\
\hline Missing & $35(0.14)$ \\
\hline Body mass index $(\mathrm{BMI})^{\dagger}$ & 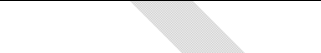 \\
\hline Normal/underweight $(<25)$ & $5162(32.70)$ \\
\hline Overweight (25-29.9) & $6919(44.68)$ \\
\hline Obese $(\geq 30)$ & $3677(21.85)$ \\
\hline Missing & $123(0.78)$ \\
\hline \multicolumn{2}{|l|}{ Perceived health ${ }^{\dagger}$} \\
\hline Poor & $765(4.03)$ \\
\hline Fair & $2128(11.20)$ \\
\hline Good & $5287(32.26)$ \\
\hline Very good/excellent & $7665(52.07)$ \\
\hline Missing & $36(0.43)$ \\
\hline \multicolumn{2}{|l|}{ Physical activity $^{*}$} \\
\hline Active & $4145(24.81)$ \\
\hline Moderately active & $3978(24.88)$ \\
\hline Inactive & $7742(50.26)$ \\
\hline Missing & $16(0.05)$ \\
\hline \multicolumn{2}{|l|}{ Type of smoker ${ }^{\dagger}$} \\
\hline Current smoker & $3020(19.25)$ \\
\hline Former/never smoker & $12714(79.92)$ \\
\hline Missing & $147(0.83)$ \\
\hline \multicolumn{2}{|l|}{ Daily consumption of fruits and vegetables ${ }^{*}$} \\
\hline$<5$ times per day & $10314(65.85)$ \\
\hline $5-10$ times per day & $4298(27.38)$ \\
\hline$>10$ times per day & $307(2.07)$ \\
\hline Missing & $962(4.70)$ \\
\hline \multicolumn{2}{|l|}{ Marital status ${ }^{\dagger}$} \\
\hline Married/equivalent & $10493(77.00)$ \\
\hline
\end{tabular}




\begin{tabular}{|l|c|}
\hline Single & $5353(22.87)$ \\
\hline Missing & $35(0.13)$ \\
\hline Country of birth $^{*}$ & $12813(70.75)$ \\
\hline Canada & $2387(24.10)$ \\
\hline Other & $681(5.14)$ \\
\hline Missing & $4816(35.67)$ \\
\hline Number of chronic health conditions & § \\
\hline 0 & $4782(30.49)$ \\
\hline 1 & $6273(33.80)$ \\
\hline$\geq 2$ & $10(0.04)$ \\
\hline Missing & $12581(80.41)$ \\
\hline Alcohol usage in the last 12 months ${ }^{*}$ & $2954(17.25)$ \\
\hline Yes & $346(2.34)$ \\
\hline No & \\
\hline Missing & $14269(83.98)$ \\
\hline Spoken language & \\
\hline $\begin{array}{l}\text { Native (English at home in ATL and ON; French at } \\
\text { home in QC) }\end{array}$ & $500(3.62)$ \\
\hline $\begin{array}{l}\text { Non-native (English at home in QC; French at home } \\
\text { in ATL and ON) }\end{array}$ & $475(7.81)$ \\
\hline Other (foreign language at home) & $637(4.59)$ \\
\hline Missing & $2119(7.11)$ \\
\hline Region (CCHS year) ${ }^{\dagger}$ & $8702(56.10)$ \\
\hline ATL (2009/10) & $5060(36.79)$ \\
\hline ON (2011/12) & 0 \\
\hline QC (2013/14) & \\
\hline Missing & \\
\hline$*$
\end{tabular}

${ }^{*}$ Taken directly from the CCHS. 'Derived from the CCHS. ${ }^{\S}$ Derived from chronic health conditions on the CCHS which include asthma, fibromyalgia, high blood pressure, migraines, chronic obstructive pulmonary disorders, diabetes, heart disease, cancer, intestinal/stomach ulcers, ailments from stroke, bowel disorder, bowel disease, mood disorders, and anxiety disorders. . CCHS: Canadian Community Health Survey; PSA: prostate-specific antigen. 
Table 3. Weighted prevalence \% estimates of lifetime PSA screening by age groups 35-39, 40$49,50-59,60-69, \geq 70, \geq 50$ and $\geq 40$ by region $(95 \%$ CIs)

\begin{tabular}{|l|c|c|c|}
\hline & \multicolumn{3}{|c|}{ Region } \\
\hline Age group & ATL (2009/10) & ON (2011/12) & QC (2013/14) \\
\hline $35-39$ & - & $5.72(3.29-8.15)$ & - \\
\hline & $24.57(19.51-29.62)$ & $27.14(23.53-30.75)$ & $11.70(8.51-14.89)$ \\
$40-49$ & {$[12.9,17.5,20.0]^{14}$} & {$[18.1]^{14}$} & {$[14.2]^{14}$} \\
\hline & $58.50(52.79-64.20)$ & $55.46(51.62-59.30)$ & $47.04(42.84-51.25)$ \\
$50-59$ & {$[45.0,41.5,43.1]^{14}$} & {$[46.3]^{14}$} & {$[44.0]^{14}$} \\
\hline & $71.82(67.15-76.48)$ & $73.22(69.95-76.50)$ & $62.96(59.16-66.76)$ \\
$60-69$ & {$[42.0,59.4,58.4]^{14}$} & {$[57.4]^{14}$} & {$[51.0]^{14}$} \\
\hline & $56.64(51.31-61.97)$ & $62.89(59.51-66.28)$ & $55.78(52.14-59.43)$ \\
$\geq 70$ & {$[43.1,44.6,44.5]^{14}$} & {$[51.4]^{14}$} & {$[48.9]^{14}$} \\
\hline$\geq 50$ & $62.77(59.49-66.05)$ & $62.74(60.53-64.96)$ & $54.40(51.99-56.81)$ \\
\hline$\geq 40$ & $50.40(47.27-53.53)$ & $51.38(49.52-53.25)$ & $42.16(39.95-44.37)$ \\
\hline
\end{tabular}

Values in [] are estimates reported in Beaulac et al. ${ }^{14}$ For Atlantic Canada, the estimates in [] are respectively for Newfoundland, Prince Edward Island, and Nova Scotia. - Not reported because of unreliable estimates. CI: confidence interval; PSA: prostate-specific antigen.

\begin{tabular}{|l|c|c|c|}
\hline \multicolumn{4}{|l|}{$\begin{array}{l}\text { Table 4. Weighted prevalence \% estimates of recent (last year) PSA screening by } \\
\text { age groups 35-39, 40-49, 50-59, 60-69, } \geq \mathbf{7 0 ,} \geq \mathbf{5 0} \text { and } \geq \mathbf{4 0} \text { by region (95\% CIs) }\end{array}$} \\
\hline & \multicolumn{3}{|c|}{ Region } \\
\hline Age group & ATL (2009/10) & ON (2011/12) & QC (2013/14) \\
\hline $40-49$ & $13.64(9.50-17.79)$ & $12.64(10.24-15.05)$ & $5.39(3.44-7.34)$ \\
\hline $50-59$ & $32.02(26.77-37.28)$ & $28.04(24.92-31.16)$ & $28.27(24.69-31.85)$ \\
\hline $60-69$ & $46.59(40.93-52.25)$ & $43.04(39.92-46.16)$ & $43.65(39.84-47.46)$ \\
\hline$\geq 70$ & $38.75(33.48-44.01)$ & $35.65(32.37-38.93)$ & $36.27(32.80-39.74)$ \\
\hline$\geq 50$ & $38.54(35.33-41.74)$ & $34.50(32.58-36.42)$ & $35.27(33.06-37.48)$ \\
\hline$\geq 40$ & $27.66(25.26-30.07)$ & $24.32(22.95-25.69)$ & $23.58(21.97-25.20)$ \\
\hline
\end{tabular}

CI: confidence interval; PSA: prostate-specific antigen. 


\begin{tabular}{|c|c|c|c|}
\hline Variable & OR & 95\% CI & $\mathbf{p}$ \\
\hline \multicolumn{4}{|l|}{$\mathrm{Age}^{\S}$} \\
\hline \multicolumn{4}{|l|}{$35-39^{\dagger}$} \\
\hline $40-44$ & 2.829 & $(1.948-4.110)$ & $<.0001$ \\
\hline $45-49$ & 5.995 & $(4.153-8.655)$ & $<.0001$ \\
\hline \multicolumn{4}{|l|}{ Household income } \\
\hline$<20000 \mathrm{CAD}$ & 0.940 & $(0.531-1.662)$ & 0.8303 \\
\hline 20 000-39 999 CAD & 0.967 & $(0.611-1.529)$ & 0.8850 \\
\hline 40 000-59 999 CAD & 1.033 & $(0.716-1.492)$ & 0.8606 \\
\hline 60 000-79 999 CAD & 0.791 & $(0.547-1.144)$ & 0.2133 \\
\hline$\geq 80000 \mathrm{CAD}^{\dagger}$ & & 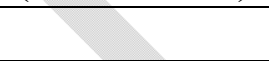 & \\
\hline \multicolumn{4}{|l|}{ Educational attainment } \\
\hline \multicolumn{4}{|l|}{ Low $^{\dagger}$} \\
\hline High & 1.081 & $(0.805-1.450)$ & 0.6053 \\
\hline \multicolumn{4}{|l|}{ Ethnicity } \\
\hline \multicolumn{4}{|l|}{ White $^{\dagger}$} \\
\hline Visible minority & 1.374 & $(0.969-1.948)$ & 0.0746 \\
\hline \multicolumn{4}{|l|}{ Had a digital rectal exam ${ }^{\S}$} \\
\hline Yes & 3.742 & $(2.857-4.901)$ & $<.0001$ \\
\hline $\mathrm{No}^{\dagger}$ & & & \\
\hline \multicolumn{4}{|l|}{ Body mass index (BMI) } \\
\hline \multicolumn{4}{|c|}{ Normal/underweight $(<25)^{\dagger}$} \\
\hline Overweight (25-29.9) & 1.198 & $(0.894-1.604)$ & 0.2263 \\
\hline Obese $(\geq 30)$ & 1.006 & $(0.710-1.425)$ & 0.9740 \\
\hline \multicolumn{4}{|l|}{ Physical activity index } \\
\hline Active & 1.083 & $(0.790-1.486)$ & 0.6206 \\
\hline Moderately active & 0.949 & $(0.695-1.294)$ & 0.7398 \\
\hline \multicolumn{4}{|l|}{ Inactive $^{\dagger}$} \\
\hline \multicolumn{4}{|l|}{ Type of smoker $§$} \\
\hline Current smoker & 0.554 & $(0.413-0.743)$ & $<.0001$ \\
\hline \multicolumn{4}{|c|}{ Former/never smoker ${ }^{\dagger}$} \\
\hline \multicolumn{4}{|c|}{$\begin{array}{l}\text { Daily consumption of fruits and } \\
\text { vegetables }\end{array}$} \\
\hline \multicolumn{4}{|c|}{$<5$ times per day ${ }^{\dagger}$} \\
\hline 5-10 times per day & 0.890 & $(0.682-1.231)$ & 0.4258 \\
\hline$>10$ times per day & 2.980 & $(1.614-5.503)$ & 0.0005 \\
\hline
\end{tabular}




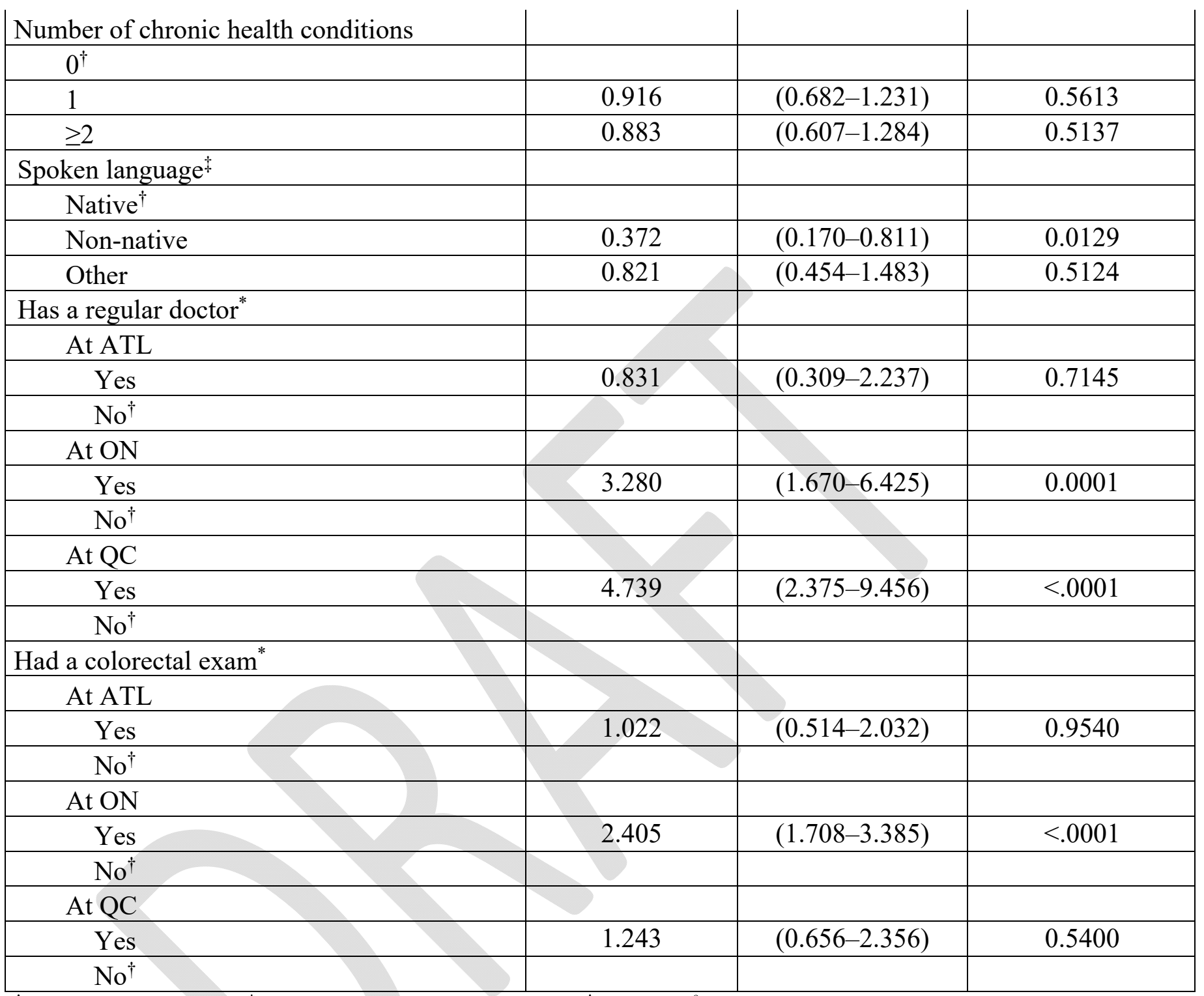

${ }^{\dagger}$ Reference category. ${ }^{*}$ Interaction terms with region. ${ }^{\star} \mathrm{p}<0.05,{ }^{\S} \mathrm{p}<0.01$ for testing whether all parameters associated with that effect are zero. CI: confidence interval; OR: odds ratio; PSA: prostate-specific antigen. 


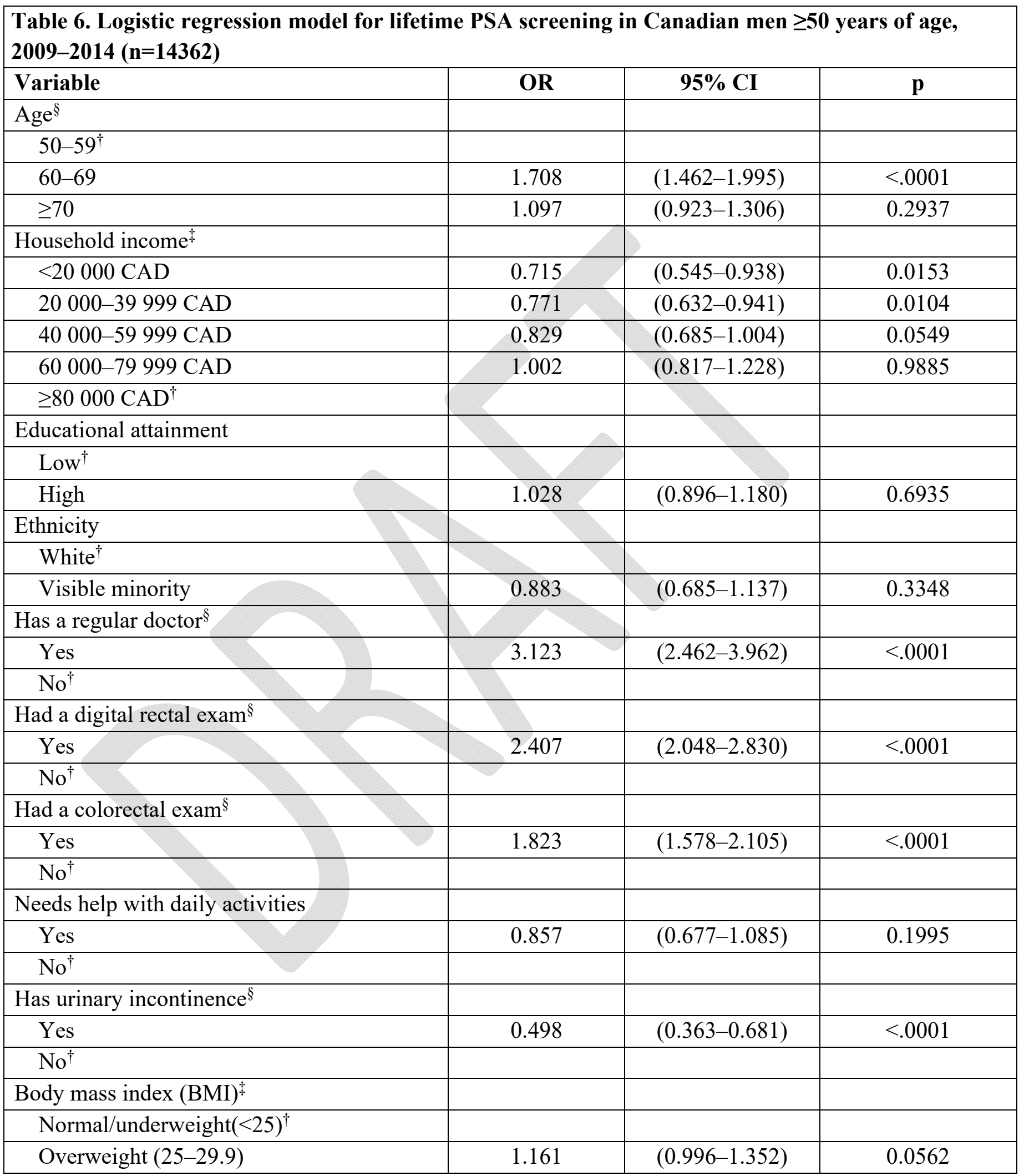




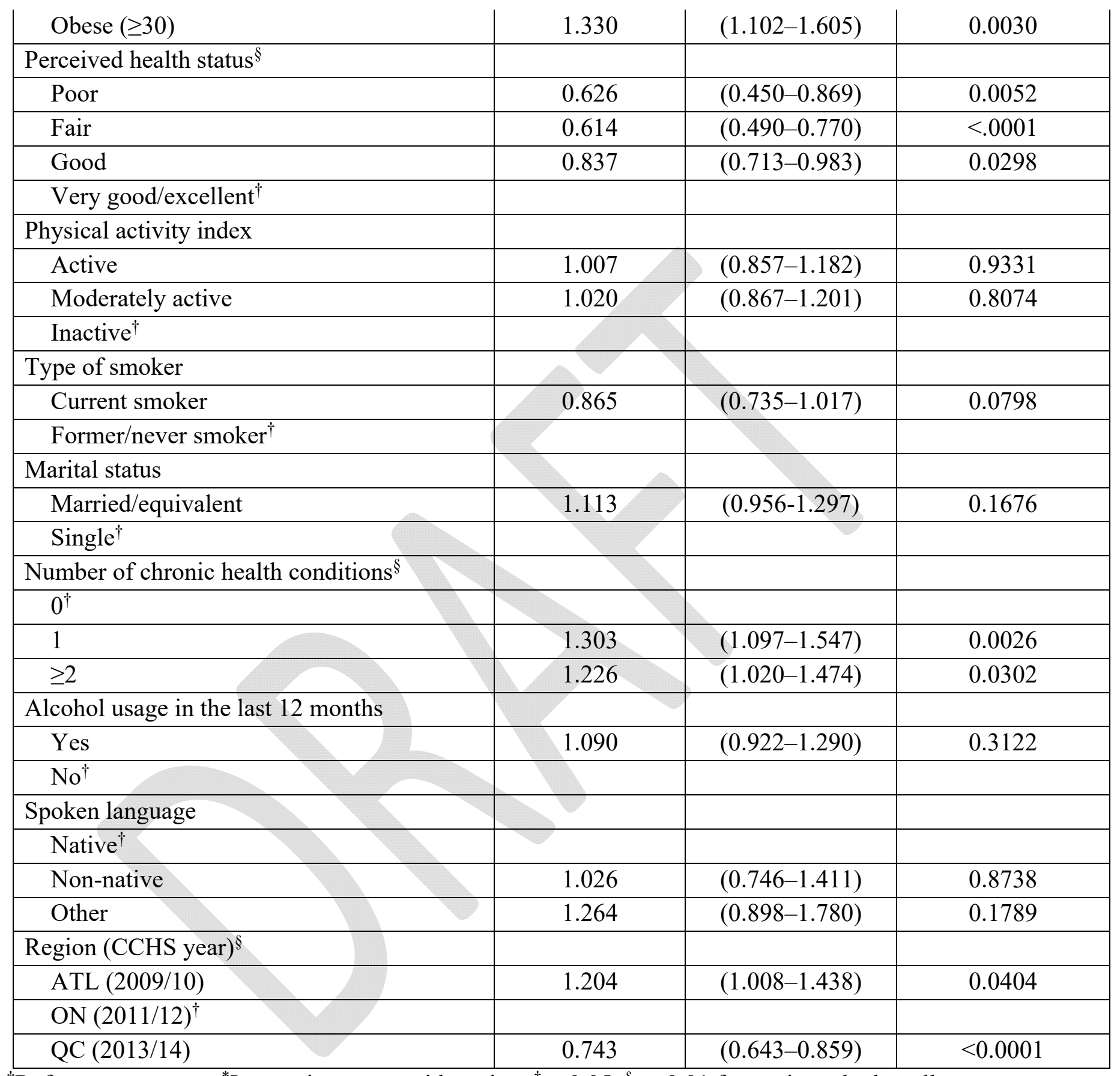

"Reference category. ${ }^{*}$ Interaction terms with region. ${ }^{\star} \mathrm{p}<0.05,{ }^{8} \mathrm{p}<0.01$ for testing whether all parameters associated with that effect are zero. CCHS: Canadian Community Health Survey; CI: confidence interval; OR: odds ratio; PSA: prostate-specific antigen. 